\title{
Four-Coordinate Iron(II) Porphyrinates: Electronic Configuration Change by Intermolecular Interaction
}

\author{
Chuanjiang Hu ${ }^{\dagger}$, Bruce C. Noll ${ }^{\dagger}$, Charles E. Schulz ${ }^{*} \ddagger$, and W. Robert Scheidt ${ }^{\star}, \dagger$ \\ $\dagger$ Department of Chemistry and Biochemistry, University of Notre Dame, Notre Dame, Indiana 46556 \\ \$Department of Physics, Knox College, Galesburg, Illinois 61401
}

\begin{abstract}
The syntheses and structures of three four-coordinate iron(II) porphyrinates are reported. The three derivatives are tetraarylporphyrin species where the aryl is either phenyl, $p$-methylphenyl, or $p$ methoxyphenyl. One of these derivatives, that of tetraphenylporphyrin, Fe(TPP), is a new crystalline phase that is distinct from the earlier reported phase (Collman, et al. J. Am. Chem. Soc. 1975, 97, 2676). This new phase of Fe(TPP) has a very saddled porphyrin core; the prior phase was ruffled. The iron atom has close interactions ( $3.10 \AA$ ) with two pyrrole $\mathrm{C}_{\mathrm{b}}-\mathrm{C}_{\mathrm{b}}$ bonds above and below the porphyrin plane. Mössbauer spectra and magnetic susceptibility measurements, different for the two phases, provide strong evidence that the two phases of Fe(TPP) have distinct electronic structures that originate from intermolecular interactions.
\end{abstract}

We report that solid state effects have a significant influence on the electronic structure of square-planar iron(II) porphyrinates. Although the electronic state of iron(II) porphyrinates have been intensively investigated both experimentally and theoretically, they are yet far from being determined (or understood) with certainty. Four-coordinate iron(II) porphyrinates or phthalocyanines are constrained by the macrocyclic ligand to square-planar coordination.

In an early theoretical investigation of $\mathrm{d}^{6}$ iron(II) with $D_{4}$ symmetry, Griffith ${ }^{1}$ noted that the orbital pattern always requires that the $d_{x 2-y 2}$ orbital be of higher energy than the other orbitals, and thus the species will always be intermediate spin $(S=1)$. Subsequently, the ground states of the intermediate-spin four-coordinate iron(II) porphyrins and phthalocyanines have been studied primarily by Mössbauer and magnetic susceptibility. The two most thoroughly investigated species are $\mathrm{Fe}(\mathrm{TPP})^{2,3}$ and $\mathrm{Fe}(\mathrm{Pc})$. Despite their expected similarities, these two species have significant differences in their Mössbauer properties and magnetic susceptibilities. ${ }^{4-8} \mathrm{Fe}(\mathrm{TPP})($ I42 $d$ ) has a much smaller quadrupole splitting value and a larger magnetic moment which indicates it has a different ground state than $\mathrm{Fe}(\mathrm{Pc})$. Most studies have assigned ${ }^{3} E_{g} A\left(\left(\mathrm{~d}_{\mathrm{xy}}\right)^{2}\left(\mathrm{~d}_{\mathrm{xz}}, \mathrm{d}_{\mathrm{yz}}\right)^{3}\left(\mathrm{~d}_{\mathrm{z} 2}\right)^{1}\right)$ as the ground state for iron(II) phthalocyanine, ${ }^{9-12}$ and ${ }^{3} A_{2 g}\left(\left(\mathrm{~d}_{\mathrm{xy}}\right)^{2}\left(\mathrm{~d}_{\mathrm{xz}}, \mathrm{d}_{\mathrm{yz}}\right)^{2}\left(\mathrm{~d}_{\mathrm{zz}}\right)^{2}\right)$ for [Fe(TPP)](I42d). ${ }^{9,13}$

As part of our investigation of iron(II) porphyrinates, we have recently isolated and structurally characterized three four-coordinate $\mathrm{Fe}(\mathrm{II})(\mathrm{Porph})$ complexes. These derivatives (Porph $=$ TPP, TTP, $\left.\mathrm{T} p-\mathrm{OCH}_{3} \mathrm{PP}\right)$ were synthesized by reduction of the corresponding $[\mathrm{Fe}(\mathrm{Porph})]_{2} \mathrm{O}$ complex. ${ }^{14}$ ORTEP diagrams for all three crystalline derivatives are shown in Figure 1; packing diagrams are given in the SI. Solvent interactions are minimal. Fe(TTP) has crystallographically imposed inversion symmetry and $\mathrm{Fe}\left(\mathrm{T} p-\mathrm{OCH}_{3} \mathrm{PP}\right)$ twofold symmetry, whereas a new phase of $\mathrm{Fe}(\mathrm{TPP})(P \overline{1})$ has no required symmetry. This complex also has a

*To whom correspondence should be addressed. E-mail: Scheidt.1@nd.edu. 
distinctly saddled core conformation, very different from those previously observed for Fe (Porph) species, all of which were either planar or ruffled. Selected structural data are listed in Table 1. Observed $\mathrm{Fe}-\mathrm{N}_{\mathrm{p}}$ distances in these four-coordinate complexes are much shorter

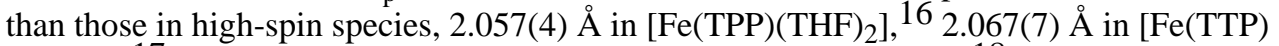
$\left.(\mathrm{THF}))_{2}\right]^{17}$ and $2.080 \AA$ in five-coordinate imidazole-ligated species, ${ }^{18}$ consistent with the expected intermediate-spin state for iron. Formal core diagrams along with averaged bond distances and angles for the porphyrin cores are given in Figure S1. As commonly observed, the saddled and ruffled $\mathrm{Fe}(\mathrm{TPP})$ complexes have shorter $\mathrm{Fe}-\mathrm{N}_{\mathrm{p}}$ distances than planar $\mathrm{Fe}(\mathrm{T} p$ $\left.\mathrm{OCH}_{3} \mathrm{PP}\right)$ and $\mathrm{Fe}(\mathrm{OEP}) .{ }^{19}$

The new $\mathrm{Fe}(\mathrm{TPP})(P \overline{\mathrm{I}})$ structure is a toluene solvate, ${ }^{20}$ quite different from the previously reported unsolvated form. The crystal packing is significantly different between the two. There are no close contacts in $\mathrm{Fe}(\mathrm{TPP})(\bar{I} 2 d)$, with the closest intermolecular approach to iron $>3.9$ $\AA$. However, for $\mathrm{Fe}(\mathrm{TPP})(P \overline{1})$, there are $\pi-\pi$ interactions between adjacent porphyrin molecules as shown in Figure 2. In this packing arrangement, adjacent porphyrin rings have individual pyrrole rings nesting into each other to form a one-dimensional $\mathrm{ABAB}$ chain. The two $\beta$-carbon atoms of adjacent pyrrole rings interact with the iron atom of the molecule above and the molecule below yielding very short intermolecular distances (3.098, $3.239 \AA$ and 3.142, 3.266 $\AA$ ). The arrangement of the two $C_{b}-C_{b}$ "double" bond interactions around the iron atom are approximately orthogonal. These ethylenic interactions and other close contacts are associated with the saddled core conformation. A similar packing arrangement, core conformation, and explanation was noted for isomorphous Co(TPP) some time ago. ${ }^{21}$

We note that the differences in iron environments are similar to those found between $\mathrm{Fe}(\mathrm{Pc})$ and $\mathrm{Fe}(\mathrm{TPP})(\bar{I} 2 d)$. The crystalline environment in $\mathrm{Fe}(\mathrm{TPP})(P \overline{1})$ leads to iron becoming pseudo-six-coordinate (Table 1). Similarly, meso-nitrogen atoms of adjacent Pc rings in centrosymmetric $\mathrm{Fe}(\mathrm{Pc})$ are $3.24 \AA$ away, generating a pseudo-six-coordinate environment for iron. ${ }^{22}$ Such axial interactions should lead to an increase in the energy of the $\mathrm{d}_{\mathrm{z} 2}$ orbital which could cause a change in relative d-orbital energy levels. Most theoretical calculations 11,25 , 26 agree that the ${ }^{3} A_{2 g}$ and ${ }^{3} E_{g} A$ states are low-lying and separated by an energy ranging from several hundred to two thousand $\mathrm{cm}^{-1}$. Mispelter's calculations ${ }^{27}$ further suggest that a small axial perturbation can induce a reverse of these two electron configurations. So the energy levels in iron(II) porphyrin could be affected by differences in crystal packing, 7,27 which could lead to different electronic configurations.

Accordingly, we have further investigated properties that could provide insight into the similarity and differences in electronic structure between the two forms of Fe(TPP). The Fe (Pc) versus $\mathrm{Fe}(\mathrm{TPP})(\overline{14} 2 d)$ dichotomy suggests that the Mössbauer quadrupole splitting values observed for $\mathrm{Fe}(\mathrm{TPP})(P \overline{1})$ would be higher than that seen for the other crystalline form of $\mathrm{Fe}$ (TPP). As shown in Table 2, that is indeed the case $(2.21 \mathrm{~mm} / \mathrm{s}$ vs. $1.51 \mathrm{~mm} / \mathrm{s})$. This quadrupole splitting value difference is consistent with a shift from a ${ }^{3} A_{2 g}$ state for $\mathrm{Fe}(\mathrm{TPP})(\mathrm{I} 42 d)$ to a ${ }^{3} E_{g} A$ state for $\mathrm{Fe}(\mathrm{TPP})(P \overline{1})$. (The similar $\mathrm{Fe}-\mathrm{N}_{\mathrm{p}}$ distances in these two phases rule out covalency effects as the factor of the $\Delta E_{Q}$ change.) The use of these simple assignments must be tempered by the recognition that all $S=1$ states are quite close in energy. ${ }^{11,25,26}$ Values of $\Delta E_{Q}$ for related species are also given in Table 2. It is seen that $\mathrm{Fe}(\mathrm{OEP})$ has a smaller $\Delta E_{Q}$ than $\mathrm{Fe}(\mathrm{OEC})$, consistent with differences in iron environments that are similar to those of $\mathrm{Fe}(\mathrm{TPP})$.

These results suggest that the magnetic susceptibilities of the two Fe(TPP) phases should also display differences with $\mathrm{Fe}(\mathrm{TPP})(P \overline{1})$ having lower values of magnetic moment over the entire range of measurements. Magnetic moments for $\mathrm{Fe}(\mathrm{TPP})(P \overline{1})$ over the temperature range $1.8-$ $300 \mathrm{~K}$ are shown in Figure 3. For comparison, the results of Boyd et al. ${ }^{7}$ for $\mathrm{Fe}(\mathrm{TPP})(\mathrm{I} 42 d)$ have also been plotted in Figure 3 (top curve). Both data sets have been fit as described in the 
figure caption. A characteristic feature of all the magnetic susceptibility fits of four-coordinate species has been a very large value of the zero-field splitting parameter, $D$.

In summary, the syntheses and structures of three new four-coordinate iron(II) porphyrinate derivatives are reported. Most significantly, the synthesis and characterization of a second crystalline form of $\mathrm{Fe}$ (TPP) has shown that weak axial interactions in the solid state are sufficient to lead to a change in the electronic character of the intermediate-spin complex with the state ${ }^{3} E_{g} A$ becoming more favorable than the ${ }^{3} A_{2 g}$ state. This conclusion is supported by Mössbauer and magnetic susceptibility measurements that have been made on both crystalline forms.

\section{Supplementary Material}

Refer to Web version on PubMed Central for supplementary material.

\section{Acknowledgements}

We thank the National Institutes of Health for support of this research under Grant GM-38401 and the NSF for X-ray instrumentation (CHE-0443233).

\section{References}

1. Griffith, JS. The Theory of Transition-Metal Ions. Cambridge University Press; London: 1961. p. 370-373.

2. Abbreviations: Porph, a generalized porphyrin dianion; TPP, dianion of meso-tetraphenylporphyrin; TTP, dianion of meso-tetratolylporphyrin; $\mathrm{T} p-\mathrm{OCH}_{3} \mathrm{PP}$, dianion of meso-tetra-pmethoxyphenylporphyrin; Pc, phthalocyanine; OEP, 2,3,7,8,12,13,17,18-octaethylporphyrinato dianion; OEC, trans-7,8-dihydro-2,3,7,8,12,13,17,18-octaethylporphyrinato (octaethylchlorinato) dianion; $\mathrm{F}_{8} \mathrm{TPP}$, dianion of meso-tetra(2,6-diflurophenyl)porphyrin; $\mathrm{TF}_{5} \mathrm{PP}$, dianion of meso-tetra (pentaflurophenyl)porphyrin; TPrPc, 2,7,12,17-tetrapropylporphycene; $\mathrm{N}_{\mathrm{p}}$, porphyrinato nitrogens; THF, tetrahydrofuran.

3. The original preparation of crystalline Fe(TPP), a crystalline phase reported by Collman et al. ${ }^{4}$ in 1975 , crystallizes in the tetragonal system and appears to be the generally studied phase. We denote this phase as $\operatorname{FeTPP}(I 42 d)$.

4. Collman JP, Hoard JL, Kim N, Lang G, Reed CA. J Am Chem Soc 1975;97:2676. [PubMed: 166106]

5. a) Dale BW, Williams RJP, Johnson CE, Thorp TL. J Chem Phys 1968;49:3441. b) Dale BW, Williams RJP, Edwards PR, Johnson CE. J Chem Phys 1968;49:3445.

6. Barraclough CG, Martin RL, Mitra S, Sherwood RC. J Chem Phys 1970;53:1643.

7. Boyd PDW, Buckingham DA, Meeking RF, Mitra S. Inorg Chem 1979;18:3585.

8. Lang G, Spartalian K, Reed CA, Collman JP. J Chem Phys 1978;69:5424.

9. McGarvey BR. Inorg Chem 1988;27:4691.

10. Li N, Su Z, Coppens P, Landrum J. J Am Chem Soc 1990;112:7294.

11. Sontum SF, Case DA, Karplus MJ. J Chem Phys 1983;79:2881.

12. Tanaka K, Elkaim E, Li L, Jue ZN, Coppens P, Landrum J. J Chem Phys 1986;84:6969.

13. Coppens P, Li L. J Chem Phys 1984;81:1983.

14. The four-coordinate species $[\mathrm{Fe}(\mathrm{II})(\mathrm{Porph})]$ was prepared by reduction of $[\mathrm{Fe}(\mathrm{Porph})]_{2} \mathrm{O}$ in different solvent with excess ethanethiol (> 200 fold) according to Stolzenberg et al. ${ }^{15}$ More detail is given in the Supporting Information.

15. Stolzenberg AM, Strauss SH, Holm RH. J Am Chem Soc 1981;103:4763.

16. Reed CA, Mashiko T, Scheidt WR, Spartalian K, Lang G. J Am Chem Soc 1980;102:2302.

17. Hu C, Noll BC, Scheidt WR. Acta Crystallogr, Sect E 2005;61:M830.

18. Hu C, Roth A, Ellison MK, An J, Ellis CM, Schulz CE, Scheidt WR. J Am Chem Soc 2005;127:5675. [PubMed: 15826208]

19. Hu C, Noll BC, Schulz CE, Scheidt WR. Inorg Chem 2005;44:4346. [PubMed: 15934765] 
20. During the writing of this communication we noted that this complex has been briefly reported: Song B, NamGoong S, Yu B. J of the Korean Chem Soc 1997;41(8):420. (This structure is not entered in the Cambridge Structural Data Base.)

21. Scheidt WR, Lee Y. J Struct Bonding (Berlin) 1987;64:1.

22. Kirner JF, Dow W, Scheidt WR. Inorg Chem 1976;15:1685.

23. Strauss SH, Silver ME, Long KM, Thompson RG, Hudgens RA, Spartalian K, Ibers JA. J Am Chem Soc 1985;207:4207.

24. a) Ghiladi RA, Kretzer RM, Guzei I, Rheingold AL, Neuhold YM, Hatwell KR, Zuberbühler AD, Karlin KD. Inorg Chem 2001;40:5754. [PubMed: 11681882] B) Oh Y, Shin BC, Swenson D, Goff HM, Kang SK. Acta Cryst 2004;C60:m57. c) Rachlewicz K, Latos-Grazyński L, Vogel E, Ciunik Z, Jerzykiewicz LB. Inorg Chem 2002;41:1979. [PubMed: 11925197]

25. Edwards D, Weiner B, Zerner MC. J Am Chem Soc 1986;108:2196.

26. Rohmer MM. Chem Phys Lett 1985;116:44.

27. Mispelter J, Momenteau M, Lhoste JM. J Chem Phys 1980;72:1003.

28. Kahn, O. Molecular Magnetism. VCH Publishers Inc; New York: 1992. p. 19 
a)

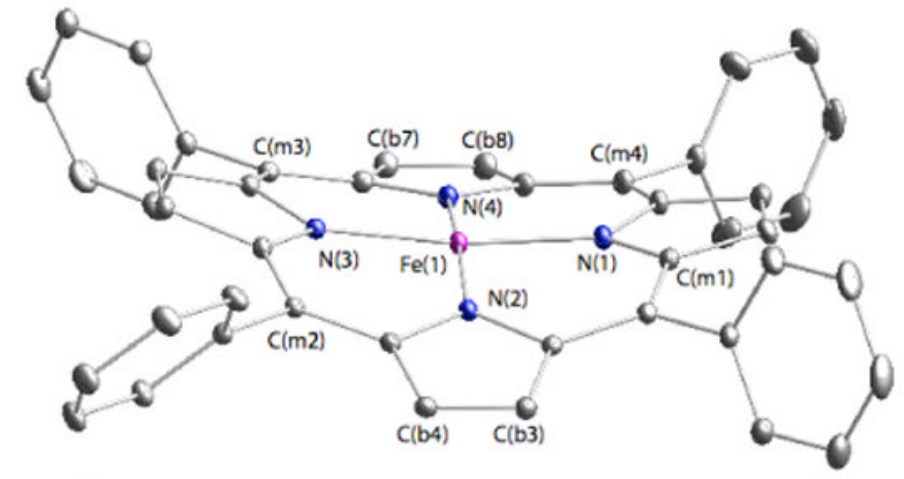

b)

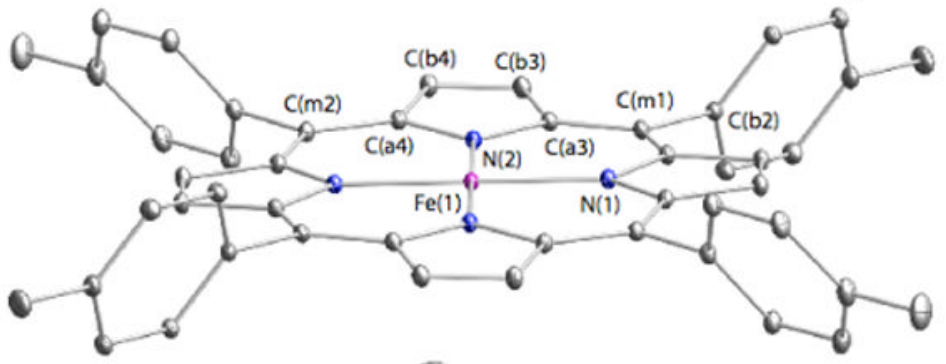

c)

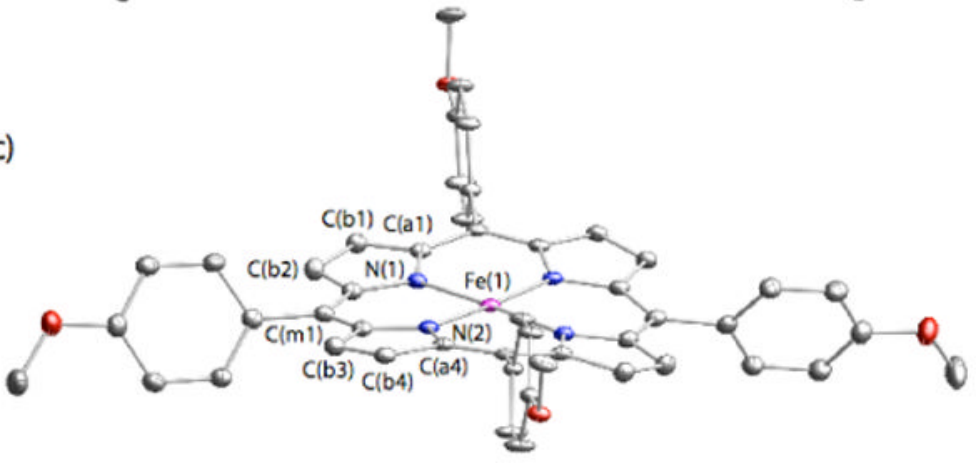

Figure 1.

ORTEP diagrams for three Fe(Porph) complexes. a) Fe(TPP) ( $P \overline{1})$. b) Fe(TTP). c) Fe(Tp$\mathrm{OCH}_{3} \mathrm{PP}$ ). The hydrogen atoms of the porphyrin ligands have been omitted for clarity. $50 \%$ probability ellipsoids are depicted. 


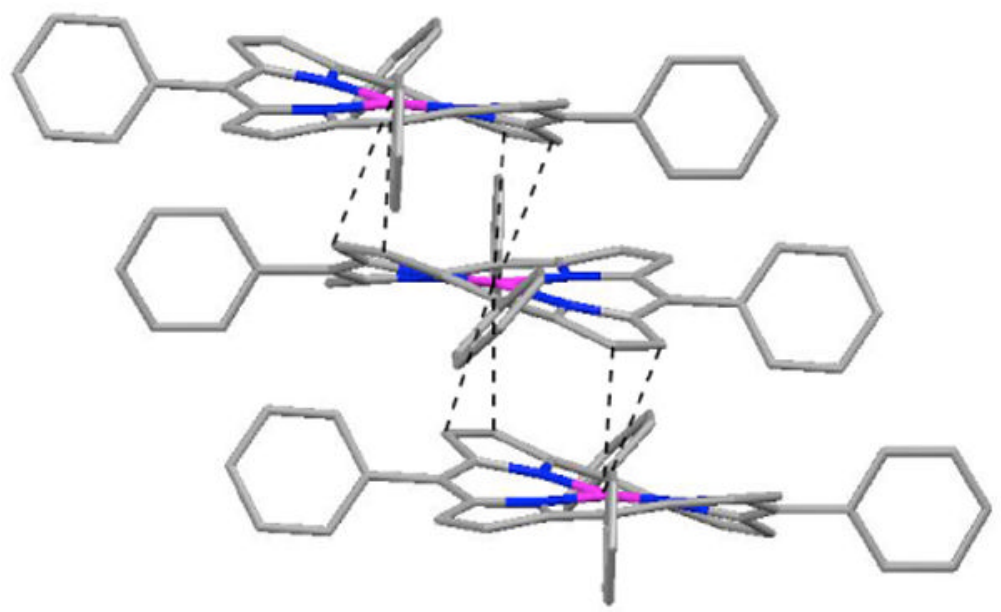

Figure 2.

Intermolecular interactions for $\mathrm{Fe}(\mathrm{TPP})(P \overline{1})$. Dashed lines link atoms with closest intermolecular distances. 


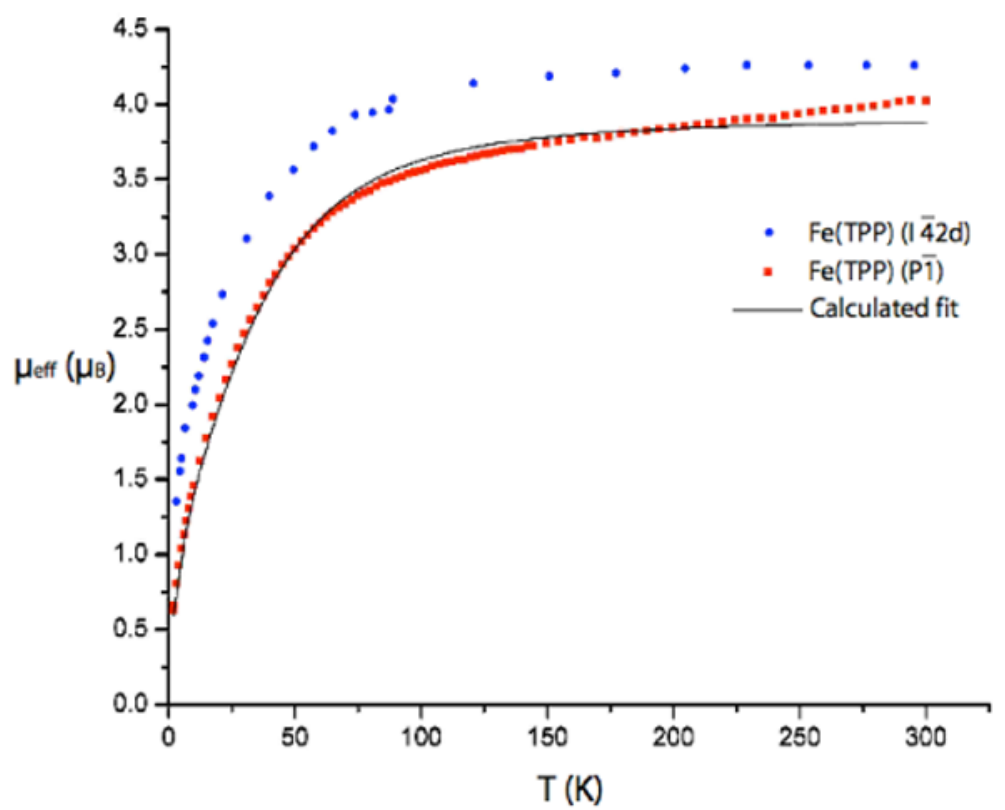

Figure 3.

Temperature dependence of magnetic moment of the polycrystalline samples. Top curve,

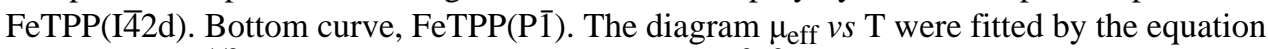
$\mu_{\text {eff }}=2.83(\chi \mathrm{T})^{1 / 2}$, where $\chi=1 / 3\left(2 \chi_{\perp}+\chi_{\| /}\right)=1 / 3\left[2 \mathrm{~N} g /{ }^{2} \mu^{2}{ }_{\mathrm{B}} / \kappa \mathrm{T}(\exp (-D / \kappa \mathrm{T}) /(1+2 \exp (-D / \kappa \mathrm{T}))\right.$ $+4 \mathrm{~N} g_{\perp} \mu^{2}{ }_{\mathrm{B}} / D((1-\exp (-D / \kappa \mathrm{T})) /(1+2 \exp (-D / \kappa \mathrm{T}))]$ as in reference 28 and $g_{/ /}=g_{\perp}=g_{\text {iso }}$. 
Table 1

Selected Structural Data for Fe(Porph) and related species.

\begin{tabular}{|c|c|c|c|c|}
\hline compound & $\operatorname{conf}^{a}$ & $\mathrm{Fe}-\mathrm{N}_{\mathrm{p}}{ }^{b}$ & $\begin{array}{l}\text { closest intermolecular distance } \\
\text { to iron } b\end{array}$ & ref \\
\hline $\mathrm{Fe}(\mathrm{TTP})$ & Pla & $1.986(1)$ & $>4.0$ & tw \\
\hline $\mathrm{Fe}\left(\mathrm{T} p-\mathrm{OCH}_{3} \mathrm{PP}\right)$ & $R u f$ & $1.976(1)$ & $>3.95$ & tw \\
\hline $\mathrm{Fe}(\mathrm{TPP})(P \overline{\mathrm{I}})$ & Sad & $1.966(2)$ & $3.10\left(\mathrm{Fe} \cdots \mathrm{C}_{\beta}\right)$ & tw \\
\hline $\mathrm{Fe}(\mathrm{TPP})(142 d)$ & $R u f$ & 1.967 & $>3.9$ & 12 \\
\hline $\mathrm{Fe}(\mathrm{OEP})$ & Pla & $1.996(16)$ & $>3.47\left(\mathrm{Fe}^{\cdots} \mathrm{C}_{\alpha}\right)$ & 23 \\
\hline $\mathrm{Fe}(\mathrm{OEC})$ & $R u f$ & $1.982(16)$ & $3.12\left(\mathrm{Fe}^{\cdots} \mathrm{C}_{\mathrm{m}}\right)$ & 23 \\
\hline $\mathrm{Fe}(\mathrm{Pc})$ & Pla & $1.926(1)$ & $3.24\left(\mathrm{Fe} \cdots \mathrm{N}_{\mathrm{m}}\right)$ & 20 \\
\hline $\mathrm{Fe}\left(\mathrm{F}_{8} \mathrm{TPP}\right)$ & Pla & 2.002 & $3.11\left(\mathrm{Fe}^{\cdots} \mathrm{C}_{\mathrm{s}}^{c}\right)$ & $24 \mathrm{a}$ \\
\hline $\mathrm{Fe}\left(\mathrm{TF}_{5} \mathrm{PP}\right)$ & Pla & $1.994(6)$ & $3.06\left(\mathrm{Fe}^{\cdots} \mathrm{C}_{\mathrm{s}}{ }^{c}\right)$ & $24 \mathrm{~b}$ \\
\hline $\mathrm{Fe}(\mathrm{TPrPc})$ & Pla & $1.915(24)$ & $3.32(\mathrm{Fe} \cdots \mathrm{C} 5 \mathrm{~A})$ & $24 c$ \\
\hline
\end{tabular}

${ }^{a}$ Predominant core conformation contribution: pla, planar; ruf, ruffled; sad, saddled.

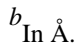

${ }^{c} \mathrm{C}_{\mathrm{S}}$, carbon atom of the solvate molecule. 


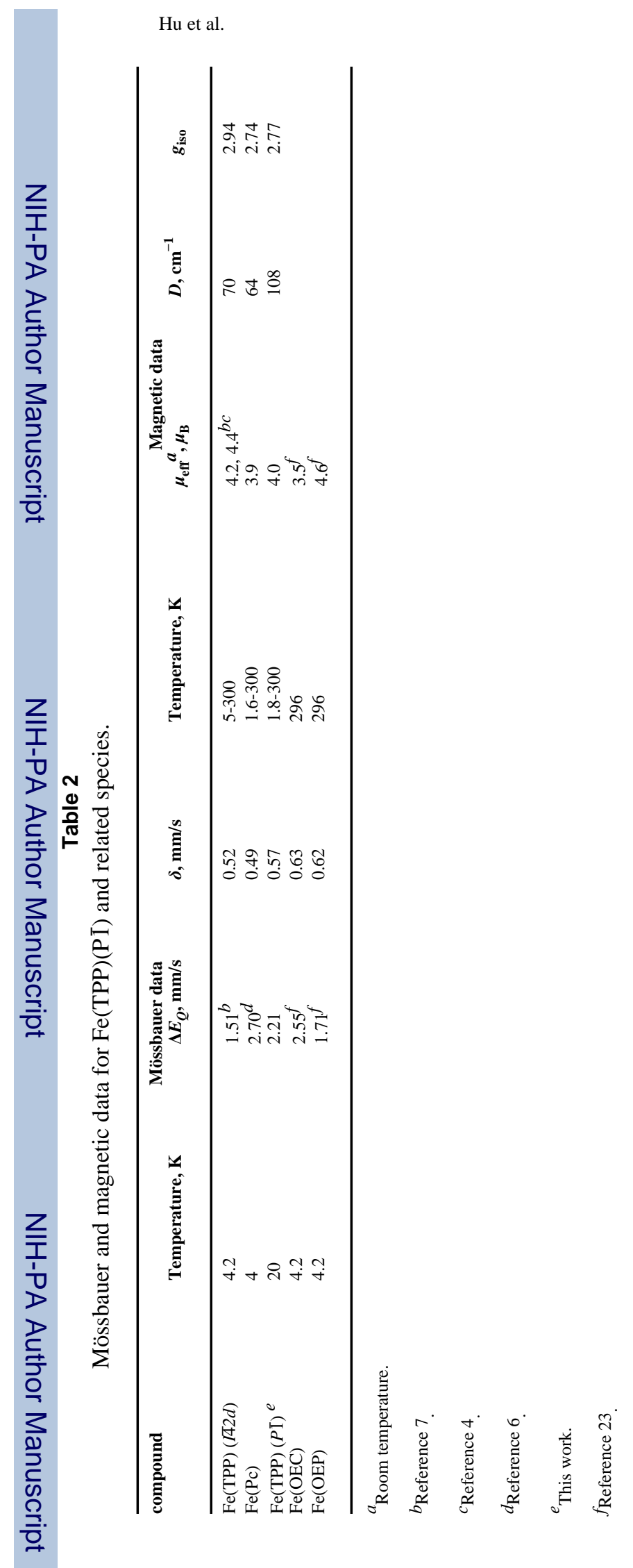

Page 9

Inorg Chem. Author manuscript; available in PMC 2008 August 12. 